\title{
KEELELISE KÜSITLUSE TÕLGENDAMISE OHUD
}

\author{
HEIKI-JAAN KAALEP
}

\section{Sissejuhatus}

$\mathrm{K}$

ui arvame, et keeleteaduslik teooria peab vastama faktidele, siis ei pääse me mööda ka küsimusest, mis on keelefakt ja kuidas seda kindlaks teha. Keelealased tähelepanekud võivad pärineda erinevatest allikatest: uurija intuitsioon, keelekorpus, küsitlus, keeleline katse. Üldjuhul peaksid eri allikad olema omavahel kooskõlas, nt kui üks väljend tundub uurijale imelik, siis sellist väljendit ei leidu ka tekstikorpustes, katseisikud väldivad tema moodustamist ja küsitlusele vastajate arvates on see väljend samuti imelik. Aga kui eri allikatest pärit faktid on omavahel vastuolus, siis tuleb kontrollida, kas faktide kogumise viis on olnud korrektne või kas keelenähtus, mida on märgatud, on üldse tõlgendatav faktina. (Nimelt mitte igasugune tähelepanek pole fakt; fakt on ainult selline tähelepanek, millel on mingi tähendus teoreetiliste seisukohtade jaoks, olgu fakt siis kinnitav, ümberlükkav või seletamist vajav.)

Allikate usaldusväärsuse probleem ilmneb mõneti võib-olla ootamatult ka sellises põhjalikult läbiuuritud valdkonnas nagu eesti keele käänamine. Alljärgnevalt vaadeldakse üht käänamise alast küsimustikku, millega algselt uuriti emakeeleõpetuse mõju ja mille tulemusi on Martin Ehala tõlgendanud kui käänamisviisi varieerumist isikuti (Sang 2012).

\section{Uurimisküsimus ja teooria}

Küsimus, millega allpool vaadeldavad faktid on seotud, kõlabjärgmiselt: kuidas oskab inimene valida sõna õige käänamisviisi? Probleem on lühidalt järgmine. Eesti keeles on sõnu võimalik käänata mitut moodi ja eesti keele kõnelejad teevad seda ilma raskusteta, kuid ei ole silmanähtav, millest lähtudes nad oma otsuseid teevad. On sõnu, mille väline kuju on väga sarnane, aga käänamisviis erinev. Teooria peaks seletama, mis määrab ära tüvevokaali valiku ühesilbilistes kaashäälikuga lõppevates sõnades, nagu näpp : näpu, käpp : käpa, räpp : räpi (teatud muusikastiil); kahesilbilistes $u k$-lõpulistes sõnades tüdruk : tüdruku, nooruk : nooruki. Või mis määrab, kas sõna muutub astmevahelduslikult või mitte, nt kinnas : kinda, pinnas : pinnase. Lisaks teaduslikule huvile on see ka eesti keele õpetamise seisukohalt kahtlemata väga oluline küsimus, sest teades, milline on käänamisviisi valimise mehhanism inimese peas, saab seda mehhanismi paremini soovitud suunas mõjutada (mille tulemusena ta hakkab töötama nii, et genereerib õigeid vorme).

Kui inimesel on vaja sõna käänata, siis juhul kui ta seda sõna varem kohanud ei ole, ei jää tal muud üle kui tugineda sõna välisele kujule ja rakendada oma keeletaju ehk keelevaistu, st keeleomaseid reegleid. Katsed, milles inimestel palutakse moodustada vorme väljamõeldud sõnadest, peaksid olema parim viis selliste keeletajuna väljenduvate reeglite tuvastamiseks. Samasuguse tu- 
lemuse peaksid andma ka päriselt olemas olevad, kuid vähe kasutatavad sõnad (nii katsetes kui ka päriselus). Tegelikust keelekasutusest (keelekorpustest) näemegi, et vähekasutatavate sõnade vormimoodustus on reeglipärane. Seejuures muutuvad sarnaste mallide järgi ka laensõnad ja pärisnimed, st nendegi käänamismallides ilmutab ennast sama keelevaist mis väljamõeldud sõnade puhul. Teisiti see ei saakski olla.

Järgnevalt mõned näited. Uued ühesilbilised, kaashäälikuga lõppevad sõnad käänduvad vältevahelduslikult, kusjuures ainsuse omastava tüvevokaaliks on - $i$ ja mitmuse osastaval -e (äpp : äpi : äppi : äppe). Kahesilbilised $u k$-lõpulised sõnad käänduvad astmevaheldusetult, tüvevokaaliks -i (nimed Taruk: Taruki ja Tobruk : Tobruki; nubuk : nubuki (teat nahk); võorruk : võõruki (teat vanuses põrsas)).

Reeglipärast käänamisviisi tajuvad keelekasutajad normaalsena, tavapärasena. Nt sõna äpp käänamine äpu või äpana tundub naljakas. Reeglipäraste sõnade arv sõnastikes on palju suurem kui erandite arv, ka tekstikorpustes on neid palju rohkem, kuid et iga üksik esineb seal keskmiselt harvemini kui ebareeglipärased, siis võivad ebareeglipärased olla tekstisõnade koguarvult isegi enamuses. Näiteks „Väikeses vormisõnastikus” (Viks 1992) on 6200 1K-tüüpi sõna, st sellist, millel rõhk on viimasel silbil, mis lõpeb kaashäälikuga (äpp, bardakk). Neist 4940 on vältevahelduslikud, tüvevokaaliks -i (1Ki). Ka keelekorpustes esineb erinevaid 1Ki-tüüpi sõnu rohkem kui muid $1 \mathrm{~K}$-tüüpi sõnu. Antud juhul on sagedusandmed ja kasutajate hinnang vormi aktsepteeritavusele omavahel kooskõlas.

Seejuures torkab silma, et kuigi eesti keeles on ühesilbilistel kaashäälikuga lõppevatel sõnadel ka muid muutmismalle, nt leem : leeme : leent; neem : neeme : neeme, siis uutele sõnadele nagu meem (meemi : meemi) nad ei rakendu; neil ei näi olevat mingit mõju keeletaju kujunemisele. Põhjalikult on nähtust kirjeldanud Kristiina Kross (1984).

Teooria seisukohalt on huvitav küsimus veel see, et kui (uue, harva) sõna väliskuju määrab tema käänamisviisi, siis kas ta määrab selle üheselt või mitte? Näiteks kas 1K-sõnade produktiivseks käänamisviisiks on ainult üks mall ja see on see, mida järgivad nii äpp kui meem? Või on see ainult kõige levinum mall ja muid on ka olemas?

Tekstikorpuste, nt TÜ Koondkorpuse (http://www.cl.ut.ee/korpused/segakorpus/) põhjal võib öelda, et ongi ainult üks mall. See on väga kategooriline väide ja teda oleks kerge kontranäidetega (kui selliseid leiduks) ümber lükata või vähemalt täpsustada. Seni pole selliseid näiteid teada. (Sõna tüng puhul tundub esimese pilgul, et kontranäide on leitud: tüng : tünga : tünga, kuid lähemal vaatlemisel selgub, et tegemist on hoopis morfoloogilise paradigma kujunemise erandjuhtumiga. Lähemalt vt lisa 1.)

\section{Nikolai Remmeli küsitlus}

1969. aastal viis Nikolai Remmel läbi küsitluse 5.-11. klassi õpilaste seas (kokku 236 õpilast), et selgitada välja, milline on nende eesti keele vaist e keeletunne (Remmel 1971); sama küsitlust kordas Tiina Tärk (2008), saades üsna sarnased tulemused. Küsitlus sisaldas ka ülesandeid sõnade käänamise kohta. Esitati väljamõeldud sõnu ja paluti vastata vajalikule küsimusele.

Osutub, et sageli on õpilaste antud vastused sellised, mida korpustel põhi- 
nev keelekirjeldus välja ei pakuks: õpilased on pakkunud (või õigeks pidanud) vorme, mis korpuste põhjal otsustades ei ole omased ei uutele (sh laen- ja slängi-)sõnadele ega harvaesinevatele sõnadele. Seetõttu tekib kahtlus, et katse tegelikult ei näita tänapäeva keele vaistu e keeletunde avaldumist, vaid midagi muud.

Toome siinkohal 15 esimest küsitluses esinenud käänamist puudutavat küsimust samas järjekorras, nagu nad esitati, õpilaste antud vastused ja ka omapoolsed vastused/kommentaarid, mis on kooskõlas tänapäevase keelekasutuse tähelepanekutega, st lähtuvad vaatest, et sõnade käänamismallide valikut saab ennustada produktiivsete ja ebaproduktiivsete mallide abil, mis on tegelikust keelekasutusest leitud. Allakriipsutatud vormid pidid õpilased juhendi kohaselt õigeks võtma.

kars om. karre, os. kart-Kas on oige?

Vastused 1971/2008: Ei Remmel (1971) ega Tärk (2008) tutvusta õpilaste vastuseid.

Kommentaar: Küsimus esitab 1K-sõna omastava ebaproduktiivse moodustusviisi kui etteantu (produktiivne oleks om. karsi) ja küsib sellele vastavat osastava vormi. Ehk teiste sõnadega, vastajale antakse ebaloomulik ülesanne: pakkuda välja erandliku käänamisviisiga sõnale sobiv mall.

reekmed / lisemed - Kuidas oleks ains. nimetav?

Vastused 1971/2008: reege 68/30, reek 14/46, muud (reekem, reekmes jne) 18/24; lise 69/78, lisem 30/19.

Kommentaar: küsimuses on esitatud mitmuse omastava vormid, mis esindavad mitteproduktiivset malli. Sellisel juhul keeletaju algvormi leidmisel ei aita, seda algvormi tuleks varasemast teada.

saruk-Kuidas oleks ainsuse omastav?

Vastused 1971/2008: saruki 49/84, saruka 46/11, saruku 5/5.

Kommentaar: ainus keelekorpustes esinevale kasutusele vastav variant oleks saruki.

sabik - Kuidas oleks ainsuse omastav?

Vastused 1971/2008: sabiku 91/85, sabika 9/5, sabiki 0/10.

Kommentaar: keelekorpuste põhjal oleks võimalikud nii sabiku kui ka sabiki, aga sabika kindlasti mitte.

mitar-Kuidas oleks mitm. omastav?

Vastused 1971/2008: mitarde 68/7, mitrade 13/0, mitrate 6/0, mitarite 0/33, mitaride 0/13.

Kommentaar: keelekorpuste põhjal oleks eelistatuim mitarite.

pokk, kas os. on pokit või pokki?

Vastused 1971/2008: Ei Remmel (1971) ega Tärk (2008) tutvusta õpilaste vastuseid.

Kommentaar: Ainuvõimalik oleks pokki.

pinnel, kas om. on pindla, pindle või pinneli?

Vastused 1971/2008: pindla 46/48, pindle 45/32, pinneli 9/20.

Kommentaar: keelekorpuste põhjal oleks ainuvõimalik pinneli.

viplade, kas ains. nim. on vipl, vipal, vibel, vipel?

Vastused 1971/2008: vipl 13/13, vipal 68/48, vibel 5/13, vipel 14/26.

Kommentaar: Millegipärast on valikute hulgast jäetud välja vipla, mis oleks tegelikult kõige sobivam.

hoim, om. hoime, kas os. on hoime või hoimet? 
Vastused 1971/2008: hoime 71/57, hoimet 29/43.

Kommentaar: küsitud on ebaproduktiivse tüvevokaaliga sõna (produktiivne oleks om. hoimi).

surras, kas om. on surrase või surda?

Vastused 1971/2008: surrase 46/43, surda 54/57.

Kommentaar: keelekorpuste põhjal oleks ainuvõimalik surrase. Remmeli (1971) arvates oli surrase aga vale vorm.

kurras, kas om. on kurrase või kurda?

Vastused 1971/2008: kurrase 43/43, kurda 57/57.

Kommentaar: keelekorpuste põhjal oleks ainuvõimalik kurrase. Remmeli (1971) arvates oli kurrase aga vale vorm.

sõrrus, kas om. on sõrruse või sõrdu?

Vastused 1971/2008: sõrruse 76/68, sõrdu 24/32.

Kommentaar: keelekorpuste põhjal oleks ainuvõimalik sõrruse. Ka Remmeli (1971) arvates oli sõrruse : sõrdu nii suur esinemine tingitud sellest, et see sõna sattus vahetult surrase järele (st Remmeli arvates tema küsitluse metoodika tingis siinkohal vale tulemuse).

letk, om. letka, kas os. on letka või letkat?

Vastused 1971/2008: letka 75/61, letkat 25/39.

Kommentaar: küsitud on ebaproduktiivse tüvevokaaliga sõna (produktiivne oleks om. letki).

piil, om. piile, kas os. on piile, piilt või piilet?

Vastused 1971/2008: piile 22/27, piilt 64/41, piilet 14/32.

Kommentaar: küsitud on ebaproduktiivse tüvevokaaliga sõna (produktiivne oleks om. piili). Kõige sagedamini valisid õpilased osastava vormiks sellise, mis on omane paarikümnele tõeliselt erandlikule, vanale sõnale (suur, keel jt).

seel, om. seele, kas os. on seele, seelt või seelet?

Vastused 1971/2008: seele 8/15, seelt 85/63, seelet 7/22.

Kommentaar: küsitud on ebaproduktiivse tüvevokaaliga sõna (produktiivne oleks om. seeli); ka muidu on olukord sama nagu eelmise sõnaga.

\section{Nikolai Remmeli küsitluse kriitika}

Kui võrrelda ühelt poolt küsitluses esitatud ülesandeid ja õpilaste antud vastuseid ning teiselt poolt seda, millised käänamismallid on vähekasutatavate sõnade puhul kasutusel tegelikes tekstides, siis on need nii erinevad, et esimesel pilgul jääb mulje, et tegemist ei ole üldse ühe ja sama eesti keelega. Aga eesti keele käänamine ei ole selle 30-40 aasta jooksul, mis eristab Remmeli katset ja tekstikorpuste allikmaterjali, väga palju muutunud.

Oletuse, et õpilased ei oska oma emakeelt, võib julgelt kõrvale jätta. Katsealused olid ikkagi juba 12-18-aastased ja earühmade vahel olulisi erinevusi ei täheldatud.

Seetõttu tuleb vaatluse alla võtta küsitluse läbiviimise metoodika.

1. Kas küsitlus uuris arvamust või käitumist? Sotsioloogiliste küsitluste puhul on tavaks pöörata tähelepanu sellele, kas küsimus käib tegeliku käitumise kohta või hoopis arvamuse või suhtumise kohta sellisesse käitumisse. Näiteks küsides „Kas uksest sisenedes on õige lasta naisterahval minna enda ees?” küsime arvamust-suhtumist, aga küsides „Millal viimati lasite naisterahva enda ees uksest sisse?” küsime käitumise kohta. Arvamused ja tegelik 
käitumine ei lähe alati kokku. Seejuures, mida võiks tähendada arvamuse küsimise puhul sõna „õige”? 1) Kas seda, et nii tuleks teha, st selline oleks hea käitumisviis (ehkki tegelikult võib-olla nii ei tehta)? 2) Või seda, et inimesed enamasti nii teevad? 3) Või seda, et vastaja ise enda arvates juhindub toodud käitumismallist?

2. Remmeli (1971) ja Tärgi (2008) küsitlused on mõlemad arvamuse küsitlused käänamise kohta, kusjuures on neil jäänud täpsustamata, mida mõeldakse „õige” all. Kas selle all mõeldakse „normingule vastav”, „enamik käänab nii” või „mina käänaksin nii”? See nüanss võib olla oluline, sest vastaja võib mõelda, et „eks ta imelik ole, aga küllap vastab normingule, seega on õige” või „mina nii ei käänaks, aga enamik vist küll”. Vajab üsna suurt enesekindlust, et öelda endamisi „See ei vasta normingule ega üldisele tavale, aga minu meelest on see õige".

Carson Schütze (2005) toob hulga näiteid keele uurimise juhtumitest, kus küsitletute vastused viitavad sellele, et nende arusaamine küsimusest oli teistsugune kui küsitlejatel. On üsna tavaline, et küsimus võimaldab mitut eri tõlgendust. Näiteks toob ta küsimuse: „Kas väljamõeldud ingliskeelse tegusõna spling mineviku vorm on regulaarne splinged või mitteregulaarne splung?" Esiteks, kui jälgida inimeste käitumist, lastes neil endil valida, kumba vormi nad oma vastuses kasutavad, siis valitakse tavaliselt regulaarne splinged, aga kui küsida arvamust, et kui sobiv on splung võrreldes vormiga splinged, siis vastavad nad, et umbes sama sobiv. Siin näeme selget analoogiat sõna „õige käänamise" mitmetähenduslikkusega eesti keele puhul: kui vastaja ise ei kasutakski seda vormi, siis tema arvates võib-olla teised ikkagi kasutaksid.

3. Milline on küsitluse kontekst? Kui oletada, et küsimus „Kas uksest sisenedes on õige lasta naisterahval minna enda ees?” esitatakse koolitusel, mille teemaks on politseioperatsioon mahajäetud majas, siis ootuspärane oleks saada hoopis teistsugune vastus kui ühistranspordi kasutamise koolitusel.

Koolis läbiviidava küsitluse puhul võib kontekst olla samuti üks segavaid mõjureid just selle osas, mida õigupoolest tähendab „õige”. Koolis pühendatakse üksjagu aega sellele, et treenida mõnede erandlike sõnade käänamist (nt susi : soe : sutt, peen : peene : peent : peeni (mitte peeneid), st surutakse nende sõnade puhul maha intuitiivset, keeletajule vastavat käänamissüsteemi. Käänamise kontekstis saab „õige” tähenduseks „veaohtliku sõna ebaintuitiivne vorm”.

Küsimustiku ülesannetest nägime, et enamik neist esitas lähteandmetena mingi erandliku muutmisviisi kui etteantu. See viis õpilased arvatavasti veelgi kindlamalt arvamusele, et siin on tegu spetsiifilise kooliülesandega, heal juhul õppeotstarbelise mänguga, kus tuleb rakendada sellele maailmale kohast keelt; päriselt tundmatutel sõnadel selliseid muutmismalle ei ole.

4. Schütze (2005) väidab, et olematu ingliskeelse tegusõna spling mineviku vormi võimalikkuse hindamisel (splinged või splung) mõjutab katseisiku otsust see, kes spling öeldakse pärinevat olemasolevast sõnastikust (sel juhul võiks sobida ka splung) või olevat ta just välja mõeldud (sel juhul sobib pigem splinged), st otsust mõjutab ettekujutus sellest, kas sõna on tundmatu omasõna või tundmatu uudissõna.

Lähtudes sõnade ebareeglipärastest mallidest, mis neile ette olid antud, ja vastusevariantidest, mille hulgas olid sellised, mis sobivad ainult vanadele, praegu mitteproduktiivse muutmismalliga sõnadele, võisid õpilased oletada, et väljamõeldud sõnad on antud juhul väljamõeldud vanad sõnad, sellised, mis oleksid võinud kunagi eesti keeles olemas olla. 
5. Küsimustele vastamine toimus enamasti valikute hulgast ühe valimise teel. Kui õpilasele oli välja pakutud mingi variant, võis ta selle valida ka juhul, kui ta ise sellist poleks välja mõelnudki. Asjaolu, et valiti just selliseid variante (küll erineva sagedusega) on arvatavasti tingitud lihtsalt küsitluse läbiviimise vormist. Ei ole alust oletada, et mitme vastusevariandi etteantus esindab adekvaatselt käändeotsuse tegemise hetke; et kui on vaja tegelikult otsustada, milline käändevorm valida, oleks silme ees korraga mitu võimalust.

\section{Kokkuvõte}

Kui soovime mõista emakeele kui kõnelejate jaoks loomuliku nähtuse käändesüsteemi, siis Nikolai Remmeli (1971) ja Tiina Tärgi (2008) küsitluste tulemusi ei ole võimalik selleks kasutada.

Praeguste teadmiste valguses saab öelda, et küsitlustes ei kajastunud adekvaatne ettekujutus sellest, mis võiks olla tänapäeva eesti keele käänamises reeglipärane ja mis erandlik, mistõttu ei osatud keeletaju uurimiseks esitada ka õigeid küsimusi.

Kuna küsitlustel on väga tõsiseid metodoloogilisi puudusi, siis nende põhjal ei saa teha järeldusi küsitletute emakeele taju kohta (ei selle kohta, milliseid vorme valitakse, ega selle kohta, milline on vormide valimise mehhanism). Saadud vastused ei ole kasutatavad kui lingvistilised faktid, mis morfoloogiateooriat kas kinnitaksid või ümber lükkaksid.

Kuid vastuseid võiks hoopis tõlgendada minevikulise keele taju avaldumisena, st sellise taju, mis võimaldaks suuremate raskusteta mõista varem käibel olnud keelt. Sisuliselt ei erine selline taju võõra murde tajust.

Artikkel on valminud sihtfinantseeritava teadusteema „Loomulike keelte arvutitöötluse formalismide ja efektiivsete algoritmide väljatöötamine ning eesti keelele rakendamine" (SF0180078s08) toel.

\section{Kirjandus}

Kross, Kristiina 1984. Eesti noomeni muutmistüüpide produktiivsus. Tallinn: Eesti NSV Teaduste Akadeemia.

R e m m e 1, Nikolai 1971. Eesti keel õpilase pilguga. Tallinn: Eesti NSV Vabariiklik Õpetajate Täiendusinstituut.

S a a r e s t e, Andrus 1979. Eesti keele mõistelise sõnaraamatu indeks. Uppsala:

Finsk-ugriska institutionen.

S a n g, Joel 2012. Mati Hindi auks. - Keel ja Kirjandus, nr 10, lk 789-790.

S c h üt z e, Carson T. 2005. Thinking about what we are asking speakers to do. -

Linguistic Evidence: Empirical, Theoretical, and Computational Perspectives.

Toim S. Kepser, M. Reis. Berlin-New York: Mouton de Gruyter, lk 457-485.

T ä r k, Tiina 2008. Eesti keel tänase õpilase pilguga: Nikolai Remmeli katse 2008.

(Emakeeleõpetuse Infokeskuse toimetised 3.) Tallinn, lk 140-151.

V i k s, Ülle 1992. Väike vormisõnastik. I-II. Tallinn: Eesti Teaduste Akadeemia.

Väike murdesõnastik II 1989. Toim Valdek Pall. Tallinn: Keele ja Kirjanduse Instituut. 


\section{Lisa 1. Tüng}

Hiljuti kirjakeelde tulnud ja praegu sage sõna tüng (tüng : tünga : tünga) 'hanekstõmbamine, altvedamine' esindab lõpuvokaali $a$ poolest suletud muuttüüpi - ootuspärane tüvevokaal oleks $i$. Kuid tema keelde tulemise viis on väga erandlik.

Andrus Saareste (1979) andmeil on sõna tüng tüvevokaaliks $a$ või $e$ ja tähenduseks 'jäänus, oks, ots, vars, hein'; „Väikese murdesõnastiku” (1989) andmeil on tüng 'tüügas, konts, roots'. Esmapilgul näib, et tänapäevane tähendus ei ole algsega üldse seotud. Kuid kõnekeeles on ammu olnud kasutusel väljend tünga panema tähenduses 'sigatsema'.

Esimesena ilmuski eesti kirjakeelde vorm tünga püsiühendite, nagu tünga tegema ja tünga saama, koosseisus, olles seega sarnane sõnadega vehkat ja plehku ühendites vehkat tegema ja plehku panema. Nii Eesti Päevalehes kui ka Postimehes ilmusid need tünga-väljendid hiljemalt aastal 1996, varasemaid esinemisjuhtumeid TÜ koondkorpuses pole. Alles hiljem hakkasid ilmuma ka muud vormid. TÜ koondkorpuse andmetel esines ajakirjas Luup 1996. aasta septembris väljend tüngasid tegema, Eesti Ekspressis esines alles aastal 1997, Eesti Päevalehes alles 1999 ja Postimehes alles 2000 esimest korda selgelt omastavaline vorm tünga. Ainsuse nimetavaline vorm tüng ilmus esimest korda Eesti Ekspressis 1998, aastal 2000 esimest korda ka Eesti Päevalehes ja Postimehes. Riigikogu stenogrammides 1995-2001 esinevad ainult väljendid tünga tegema (1998) ja tünga saama (1999), sõnavormi tüng ei esine kordagi.

Saame vast väita, et käänamisviis tüng : tünga ongi kandunud meie päevini väljendi koosseisus, analoogiliselt sõnaga plehku väljendis plehku panema.

Seega võib öelda, et sõna tüng ilmus kirjakeelde oma praeguses tähenduses mitte kohe täistähendusliku sõnana, vaid algul käändumatu vormina ühendite koosseisus, seejärel lisandusid keelde ainsuse omastava ja mitmuse osastava vorm. Alles seejärel ilmus ainsuse nimetava vorm tüng, mis on esimesena keelde ilmunud vormist tüvevokaali võrra lühem. Nii et sõna tüng keelde (taas)tuleku viis erineb tavapärasest uuest sõnast (nt äpp), mis keelde tulemise hetkel on just nimelt ainsuse nimetavas käändes ja millele alles seejärel lisandub tüvevokaal. Tüng aga tuli koos tüvevokaaliga $a$.

Võib öelda, et tünga käänamisviis, just temale rakendatavana, oli olemas enne, kui sõna ise taas täistähenduslikuks muutus, päris käändsõnaks sai.

\section{Risks in the interpretation of linguistic questionnaires}

Keywords: Estonian declensional system, linguistic evidence, methodology

The article investigates in detail a study aimed at eliciting word inflection acceptability judgements. The article points out the methodological weaknesses of the questionnaire and concludes that the results cannot be used as linguistic evidence for studying the contemporary Estonian morphological system.

Heiki-Jaan Kaalep (b. 1962), PhD, University of Tartu, Institute of Estonian and General Linguistics, senior researcher, heiki-jaan.kaalep@ut.ee 